\title{
Factors influencing the outcome of the Medical-Psychological Assessment of speed-affine drivers in Germany
}

\section{T. Wagner, L. M. Uhlmann, D. DeVol \& I. Rethfeldt}

\begin{abstract}
In Germany, offenders with severe or repeated violations of traffic rules are required to pass a Medical-Psychological Assessment (MPA) to regain their driving licence. The most common offence is speeding. The present research analysed 104 MPA files from speeding offenders in order to determine whether delinquency-related variables or characteristics of the driver's behaviour change process predicts the MPA outcome (positive or negative relapse risk). The results show that characteristics of the offences themselves (e.g. the number of speed violations) do not serve as valid predictors. However, whether the offenders had voluntarily participated in a driver improvement program prior to the MPA did predict the MPA outcome. Moreover, the most suitable predictors were problem awareness and self-criticism demonstrated in the psychological assessment. Furthermore, the results underpin the suitability and utility of the MPA as a measure to evaluate relapse risks.
\end{abstract}

KEYWORDS: speeding; repeat offender; Medical-Psychological Assessment, MPA; relapse risk

\section{INTRODUCTION AND LITERATURE REVIEW}

Speeding is a serious, yet common offence, often related to mobility in a stressful modern world or a driver's pleasure seeking behaviour (Berry, Johnson \& Porter, 2011; Shinar, 2017). In this paper, we use the term speeding to refer to the act of driving faster than the applicable speed limit and the term speedaffine drivers to refer to a specific group of drivers who have a strong tendency towards speeding, which is motivated by personality dispositions (Berry et al., 2011; Wagner, Keller \& Jäncke, 2018).
Collision statistics suggest that around $30 \%$ of all fatal crashes are a direct result of unadjusted speed (SafetyNet, 2009). Interestingly, an Australian study demonstrated that speeding can be as dangerous as driving under the influence of alcohol, with the increase in speed akin to an increase in blood alcohol concentration (BAC). Specifically, speeding at $5 \mathrm{~km} / \mathrm{h}$ above the speed limit of $65 \mathrm{~km} / \mathrm{h}$ is comparable to driving under the influence of alcohol with a BAC of $0.5 \%$. Exceeding the speed limit by $10 \mathrm{~km} / \mathrm{h}$ is associated with the related accident risk as driving with a BAC of $0.8 \%$ (Kloeden, McLean, Moore \& Ponte, 1997). Aside from this, speeding also has a negative impact on the environment because of air and noise pollution.

Despite the known risks, speeding remains a mass phenomenon amongst drivers with $40-60 \%$ of drivers habitually exceeding the speed limit and about $10-20 \%$ driving constantly $10 \mathrm{~km} / \mathrm{h}$ too fast (SARTRE III, 2004). According to the same study, $80 \%$ of the drivers from 23 EU countries agreed that speeding is an important cause of accidents. Shinar (2017) stated that this issue is attributed to drivers considering themselves to be safe, despite acknowledging that they often exceed the relevant speed limit. Consistent with this suggestion, Rößger, Schade, Schlag and Gehlert (2011) interviewed 1009 drivers and observed that speeding is tolerated, even among those people who accept traffic rules in general. They also observed that drivers' speed compliance is predicted by informal norms, habits, situational factors and the subjective evaluation of risk and severity of punishment. This subjective evaluation is in the end of course influenced by the real frequency of enforcement. An increased enforcement density or even the continuous information about enforcement may result in significantly lower frequencies of speeding (Hössinger \& Berger, 2012). 
Whilst traditional research has investigated speeding behaviour as a dependent variable (Berry et al., 2011), recent studies have focused on speeding in combination with other road violations and the driver's criminal history (Watson, Watson, Siskind, Fleiter \& Soole , 2014; Wagner et al., 2018). With this in mind, driving too fast can be seen as a "syndrome" of maladaptive behavioural patterns (Wagner et al., 2018; Watson et al., 2014). For example, Wagner et al. (2018) conducted a study among drivers from Germany and Switzerland $(\mathrm{N}=361)$, demonstrating that a risk-prone subgroup of drivers exists (named impulsivity subtype), and that they appear to be speed-affine i.e., they have a strong tendency towards speeding behaviours. The members of this subtype tended to score high in impulsivity, low on compliance, high on affective responsiveness and described themselves as affordance-prone for breaking traffic rules when situational conditions are quite favourable, e.g. passing a red traffic light. With regard to traffic delinquency, these drivers reported having more speeding offences in their driving licence file, as well as admitting to overriding speed limits for more than $15 \mathrm{~km} / \mathrm{h}$ more frequently. They also committed criminal acts with regard to aggression, vandalism, assault or robbery more often compared to other less risky subtypes. In line with these findings, Sucha and Cernochova (2016) compared speed-affine drivers, who had had to pass a traffic psychological examination because their licences had previously be revoked due to serious traffic violations, to a group of control drivers. They observed that the speed-affine drivers showed lower scores in conscientiousness, agreeableness, less selfcontrol and responsibility and more sensation seeking and non-conforming behaviour.

Watson et al. (2014) investigated data from 84,465 drivers in Australia and identified a subgroup they labelled "high-range offenders". These individuals had committed two or more speeding offences with a recorded speed of $30 \mathrm{~km} / \mathrm{h}$ or more above the speed limit in a specific timeframe (May 1996 to August 2007). In comparison to other drivers, the highrange offenders were more likely to be male, younger than 30 years old, were more likely to be in an accident, and had more traffic offences and even criminal offences in their record. This led to the conclusion that high-range offenders show a reduced ability to comply with norms in the traffic domain and beyond. As explained later in this paper, these people would receive hypothesis V2 in the German MPA process (DGVP \& DGVM, 2013).
Extending beyond previous research, which has included a myriad of personal, social, situational and legal factors (see also Wagner, Keller \& Jäncke, 2018) to explain speeding behaviour, it also seems worthy to examine factors that can moderate speeding behaviours in order to improve road safety. Thus, we structured this paper in the following way. First, it is to be acknowledged that speeding in Germany is generally tolerated and that the negative judicial consequences are negligible in cases of a (minor) single offence. Second, we present a brief description of the Medical-Psychological Assessment (MPA), which has been introduced as a measure to improve road safety in Germany. Third, we present an empirical study that investigates the contribution of drivers' traffic delinquency features (e.g. the number of speed violations), benefits of a professional driver improvement program (DIP) and findings from a psychological assessment for the prediction of the MPA outcome. This will also allow us to determine whether the MPA is a valid measure to enhance road safety. It should be noted, that this is the first empirical study addressing this topic.

\section{SPEEDING OFFENCES IN GERMANY}

Speeding is one of the leading factors of collisions in Germany with about $30 \%$ of all fatal accidents as a direct result of a failure to adhere to the speed limit. Furthermore, more than $50 \%$ of all entries in the Central German Register of Traffic Offenders are speeding offences (Wagner, Keller \& Jäncke, 2018). These statistics are particularly alarming given the relatively mild consequences an offender faces if caught speeding. For example, if one drives more than $20 \mathrm{~km} / \mathrm{h}$ above the limit they would have to pay a maximum fine of 35 euros. If one exceeds the limit for more than $50 \mathrm{~km} / \mathrm{h}$, the fine is around 240 euros, along with a driving ban for one month. In comparison to other EU-states the German fines range at the bottom level. Specifically, for the same offence of driving more than $20 \mathrm{~km} / \mathrm{h}$ above the limit in France, a driver would have to pay a minimum of 135 euros; however, for the offence of driving more than $50 \mathrm{~km} / \mathrm{h}$ above the limit, they would have to pay 1,500 euros. Surprisingly, there is no speed limit on German motorways, though it is recommended that the drivers keep to a so-called advisory speed limit ("Richtgeschwindigkeit") of $130 \mathrm{~km} / \mathrm{h}$. However, without legal reinforcement or consequences this advisory limit is largely 
ignored. On the other hand, in accordance with $\S 3$ section 1 of the road traffic ordinance (= "Straßenverkehrsordnung", a legal regulation level below the road traffic act), it is the drivers responsibility to ensure that their driving speed is suitable with regard to road and weather conditions, sight and traffic density. Additionally, they must ensure that their driving style prevents others from harm, injuries and inconveniences (basic traffic rules according to $\S 1$ of road traffic ordinance). If the driver ignores the advisory speed limit on motorways, thereby being involved in an accident, he has to accept a joint liability of around about $20 \%$ of the accident-related costs. This is true if the accident could have been prevented by driving at the advisory speed limit. In these cases, liability is determined in court on the advice of expert witnesses trained in technical accident analysis.

The negative legal consequences for speeding combine fines and driving bans with penalty points. In the case of a severe traffic offence (e.g. after joining a road race) or when the maximum of 8 penalty points is exceeded, the driving licence is revoked. In order to regain their licence the driver must pass a Medical-Psychological Assessment (MPA). The MPA represents a specific kind of examination that can be seen as an element of the popular concept of the four E's (e.g., education, enforcement, engineering, examination) to improve road safety (Groeger, 2011). The core idea of the MPA is to estimate the driver's future on-road risk and to give this information and advice, in the form of an expert report, to the driving licence authority.

\section{MEDICAL-PSYCHOLOGICAL ASSESSMENT (MPA) IN GERMANY}

Here we present a very short description of the MPA-procedure, however, for more information about this expert system, see Brenner-Hartmann et al. (2014). When people receive their driving licence in Germany they are automatically assumed to be fit to drive until they severely or repeatedly violate traffic rules or laws. All traffic offences registered by the police are recorded in the Central Index of Traffic Offenders in accordance with the German penalty point system. On January 1st, 2017, 10,100,000 people had a recording in the Central Index of Traffic Offenders, with 5,961,000 of these classed as speeded offences (Kraftfahrt-Bundesamt, 2018). Yearly around 90,000 drivers have to pass an MPA. In 2017, this number was 88,035 , with $18 \%$ of those offences not being the result of an impairment from driving under the influence of alcohol or drugs (Bundesanstalt für Straßenwesen, 2018).

To ensure that the diagnostic process is applied using standardized methods and assessment criteria, the scientific principles of MPA are summarized and defined within two important publications:

1. The guidelines for the evaluation of driver fitness of the Federal Highway Research Institute (Begutachtungsleitlinien zur Kraftfahreignung. Bearbeitet von Gräcmann, N., Albrecht, M., Bundesanstalt für Straßenwesen Verkehrsblatt Dokument Nr. B 4022, 2017)

2. Assessment criteria collected in Urteilsbildung in der Fahreignungsbegutachtung - Beurteilungskriterien (DGVP \& DGVM, 2013), supporting the assessors as an expert working tool, including decision strategies of collecting and evaluating individual findings according to specific principles.

Assuming that there is a distinct rational behind the individual's offending behaviour, the MPA begins with the specific question of "Might we expect $\mathrm{Mr} / \mathrm{Mrs} \mathrm{X}$ realising further traffic offences in the future?" This initial question governs the following diagnostic process. In order to determine the individual's risk of reoffending, both a physician and a psychologist work together. The physician focuses on checking the general health of the individual, for example, they will check their vision and check for any health impairments, such as neurological disorders or attention deficit hyperactivity disorder (ADHD), which might be the reason for the traffic violations. Conversely, the psychologist firstly conducts a licence file analysis to gain a clear understanding of the driver's offending history. Following this, they can prepare a psychological interview. The interview has a structured dialogue to assess the client's problem awareness, self-criticism, and stability of changes in attitudes and behaviour according to the assessment criteria. The conclusive decision of whether the person is fit to drive is determined by the interview findings with regard to the evaluation criteria. It also gives a profile of personal resources to be changed to meet the requirements for a positive MPA prognosis, i.e., driving licence is regained.

The assessment criteria follow a hierarchical structure according to the diagnostic hypotheses, be- 
ginning with the most serious disorder and moving on to less severe maladaptive behavioural patterns. The hypothesis includes a statement about the diagnostic assessment and the derived requirements for behavioural changes (DGVP \& DGVM, 2013). The most severe hypothesis V1 (adjustment or personality disorder) is rare and not part of this study. Hypothesis V2 states that the rule violations are a result of an reduced adjustment ability, whereas clients receiving hypothesis $\mathrm{V} 3$ have a reduced motivation to comply with traffic rules. In order for a psychologist to be qualified to perform MPAs they must have worked for two years as a professional psychologist after completing their diploma or master's degree. They must then pass additional training in traffic psychology, run a minimum of 100 MPAs under supervision for one year and complete three days of continuing education each year. Following this training and experience, the traffic psychologist is then allowed and able to perform the MPA and distinguish between the three risk categories (V1 to V3). In addition to that, there are further hypotheses (e.g. V4: a disease, such as sleep apnoea, caused the offences) that have to be tested during the MPA. Those have nothing to do with attitudes or behavioural patterns, therefore they were not included into this study. For example, he will choose V2 hypothesis if several of the following criteria are true:

- repeated relapse after a former positive MPA or repeated licence revocation.

- relapse after participation at a driver improvement program with legal consequences.

- heterogeneous offences including both traffic and criminal offences.

- driving under the influence of alcohol or drugs (in addition to a speeding episode).

- the list of offences is characterized by an escalating severity or dysfunctional dynamics, i.e. persistent disregard of legal regulations, starting with mild administrative offences, later criminal offences.

- a considerable number of severe violations or serious criminal acts (followed by a prison sentence).

Since the underlying problem for the V2 hypothesis is more severe than V3, the criteria that have to be fulfilled to achieve a positive MPA result are more demanding. In German administrative law, the MPA is considered to be a prognosis of future traffic delinquency, but not in the sense of a statistical prognosis where measurable criteria of the future on-road-performance are collected. It is rather an expert's prognosis on whether a person, that has severely or repeatedly violated traffic rules or laws in the past, now shows stable changes in their personality, i.e. giving an answer to the initial question "Might we expect Mr/Mrs X realizing further traffic offences in the future?".

This paper intends to demonstrate the model fit of MPA. To achieve this, the study uses data in which different traffic psychologists have all used the same system (as described above) for the collection and evaluation of findings and have applied diagnostic strategies in a homogeneous way. We predict that speed-affine elements or traffic delinquency history are independent from the further tendencies to offend, as judged by a positive MPA result. Instead, a positive MPA should rely on the characteristics of the driver's coping process (as indicated by participation at a DIP) and correcting their problem awareness towards safety attitudes and beliefs and enhancing self-criticism. Of particular interest is the relative contribution of the different predictors for the final MPA result.

\section{METHODS}

\subsection{Data base}

The data were taken from written MPA-reports provided by the DEKRA MPA Centre in Dresden, Germany. A total of 110 of these case files fulfilled the requirement of at least 2 speeding offences followed by an MPA from January 2014 until March 2017, representing the speed-affine risk category according to Watson et al. (2014). All of the sample underwent the MPA because of severe or repeated traffic rule violations. None of the cases were selected due to DUI (driving under influence) offences.

A total of 6 of the people had undergone MPA assessment at the same place twice in the timeframe, therefore their data appeared twice. We only included the earlier MPA data. From the remaining 104 cases, 3 received a so-called $\mathrm{H} 0$ hypothesis, meaning they failed to cooperate or provide the assessor with relevant information to answer the MPA question. Those MPAs receive a negative result by default and were therefore excluded from the analysis. This resulted in 101 valid cases for analysis. The drivers in the sample analysed (96 male, 5 female) ranged in age 
from 18 to 68 years (Mean $[\mathrm{M}]=36.03$, Standard Deviation $[\mathrm{SD}]=12.40)$. Age was calculated as age at last speeding offence - this was done because it is possible that several years can pass between licence withdrawal and MPA. The overall MPA outcome was $43.6 \%(\mathrm{~N}=44)$ positive and $56.4 \%$ negative. A total of 41 people received the more severe $\mathrm{V} 2$ hypothesis and 60 people received the milder $\mathrm{V} 3$ hypothesis. The number of speeding offences per person ranged from 2 to $11(\mathrm{M}=4.44, \mathrm{SD}=2.11)$. No cases of $\mathrm{V} 1$ were observed in the data.

\subsection{Method of data collection}

MPA files include questionnaires about personal information filled in by the participant, detailed information about the offences from the Central Index of Traffic Offenders, criminal records, and certificates about participation in DIP. The file also contains the detailed file analysis of the psychological assessor and a copy of the entire MPA report. For each participant, 11 variables were collected and coded. Details about the variables, coding, and source of information can be obtained from table 1 .

The result of the MPA as an outcome variable was extracted; as well as demographic variables such as age and gender. The collected predictors were reported hypothesis, voluntary participation at DIP prior to the MPA, problem awareness, selfcriticism, and four offence characteristics with regard to speed-affine driving style and traffic delinquency history. In more detail, we summarized the number of speeding offences prior to the licence revocation and calculated the sum from the amount of $\mathrm{km} / \mathrm{h}$ of the speed limit transgression across all speeding offences. More speeding offences with a high transgression of speed limits indicate probably a more serious adjustment problem, making it potentially more difficult to change the behaviour and achieve a positive MPA result. Another important variable is the temporal distribution, which is the proportion of offences committed in the last year before licence revocation compared to all committed offences. More offences committed in the relatively short period of one year, indicating an escalating dynamics in the distribution of traffic delinquency history, might be another indicator for a deeper adjustment problem. Finally, we counted the number of all non-speeding offences in the original offence file, for example using a mobile phone while driving, red light running, and hit-and-runs or driving without a valid licence. A heterogeneous mixture of offences also indicates a more serious behavioural problem in terms of hypothesis V2.

Table 1: Variable details and coding

\begin{tabular}{|c|c|c|}
\hline Variable name & levels & source of information \\
\hline gender & male-female & copy of MPA report \\
\hline age & at the time of the last speeding offence & original offence file \\
\hline MPA result & $0=$ positive, $1=$ negative & copy of MPA report \\
\hline report hypothesis & $0=\mathrm{V} 2 ; 1=\mathrm{V} 3 ; 2=$ other* & copy of MPA report \\
\hline number of speeding offences & 2 to 11 & original offence file \\
\hline $\mathrm{km} / \mathrm{h}$ above speedlimit & sum score over all speeding offences & original offence file \\
\hline $\begin{array}{l}\text { temporal distribution: proportion of offences } \\
\text { committed in the last year before licence } \\
\text { withdrawal of all offences }\end{array}$ & between 0 and 1 & original offence file \\
\hline $\begin{array}{l}\text { number of all non-speeding offences in } \\
\text { the original offence file }\end{array}$ & 0 to 9 & original offence file \\
\hline participation in DIP prior to the MPA (voluntarily) & $0=$ yes $; 1=$ no & submitted certificates \\
\hline problem awareness & $0=$ existing $; 1=$ not existing & psychological assessment \\
\hline self-criticism & $0=$ existing; $1=$ not existing & psychological assessment \\
\hline
\end{tabular}

* Please note that „other“ means “other hypotheses”, such as V4. As only V2- and V3-hypotheses were included, “other” has the value $\mathrm{N}=0$. It was used to cross-check the data. 


\subsection{Methodical procedure}

Written case reports from 5 experienced traffic psychologists and their assessment outcomes across the sample $(\mathrm{N}=101)$ were analysed in March 2017. All statistical analyses were performed with IBM SPSS (Version 22). There were no missing values. The alpha level of significance was set at 0.05 .

In order to obtain an overview of the relationships between the variables, a bivariate correlation analysis was performed on the data.

A hierarchical (also called stepwise) logistic regression was then performed on the data to determine which of the variables predicted MPA outcome. Logistic regression analysis has to be used instead of linear regression analysis since MPA outcome is a binary variable (can only have the value positive or negative), not a continuous variable.

On the first level, the four characteristics of the speed-affine driving style and traffic delinquency history were entered into the model, here we expected no relationship with the MPA-result. The second level adds the reported hypothesis (e.g. V2, or V3) as a predictor variable. As the hypothesis represents the severity of the person's maladaptive traffic behaviour this issue should be relevant for the MPA result. On the third level, the participation at a driver improvement program (which is not mandatory by legal regulations) was entered into the regression. Since problematic attitudes and behaviours are addressed within this measure, participants might benefit from the settings. This should lead to more positive MPA results. Finally, problem awareness and self-criticism (both demonstrated in the psychological interview) were entered into the last block of the prediction model. With regards to the MPA expert system, these factors are essential for the decision on the MPA result and should be the strongest predictors. Although Watson et al. (2014) state that “... high-range offenders were more likely to be male, younger than 30 years old, ..." we did not include age and gender in those analyses, since there is no theoretical foundation why these factors should influence the MPA outcome itself. In addition, there were only 5 women in the sample, which is not enough for a meaningful statistical interpretation.

\section{RESULTS}

Table 2 shows pairwise computed Pearson correlation coefficients among all variables used in the study. The result of the MPA is correlated negatively to reported hypothesis $(r=-.36, p<.001)$, indicating that people with $\mathrm{V} 3$ hypothesis are more likely to receive a positive result. As expected, there is no correlation with the characteristics of the speeding offences (indicative of speed-affine behaviour) and the MPA result. On the other hand, positive correlations were observed between MPA result and participation at DIP $(\mathrm{r}=.471, p<.001)$, problem-awareness (Cramers's V $\Phi=.80, p<.001$ ) and self-criticism as demonstrated in the psychological interview (Cramers's V $\Phi=.7, p<.001$ ). The characteristics of the speeding offences do not correlate among each other, except for a negative correlation between $\mathrm{km} / \mathrm{h}$ above the speed limit and number of non-speeding offences, as well as a positive correlation between number of speeding offences and $\mathrm{km} / \mathrm{h}$ above the speed limit. This was expected, since $\mathrm{km} / \mathrm{h}$ above speed limit was computed as a sum score, meaning more speeding offences result in a higher $\mathrm{km} / \mathrm{h}$ number. Problem awareness and self-criticism are positively related to each other and to participation in a DIP and negatively related to the reported hypothesis.

As a next step, we performed a hierarchical logistic regression analysis as described above in order to estimate the contribution of the predictors for the final MPA outcome/prognosis. To assess whether multicollinearity might be a problem in our data, we looked at the Variance Inflation Factors (VIF) and the collinearity diagnosis. Both tests, implemented in SPSS to check for multicollinearity, indicated that this is not a problem in our data. The results of the hierarchical logistic regression analysis can be seen in table 3 . Here, the $2^{\text {nd }}$ column expresses the predictors entered in the equation, the influence on the outcome variable is displayed by beta-coefficient (b) and whether this influence is statistically significant. Nagelkerkes $\mathrm{R}^{2}$ is a measure of how well the model fits the data, with 0 indicating no fit at all and 1 indicating a perfect fit. It can be interpreted analogically to $\mathrm{R}^{2}$ adjusted in linear regression analysis.

The quality of classification describes the classification result (positive or negative MPA outcome) based on the predictor entered in the model. $100 \%$ means every participant was sorted into the correct group and $50 \%$ indicates a classification at chance level.

If only the four offence characteristics are used, the classification is indeed close to chance level (56.4 \%) with a very small Nagelkerkes $\mathrm{R}^{2}(.015)$. In 
Table 2: correlations between the variables

\begin{tabular}{|c|c|c|c|c|c|c|c|c|c|}
\hline & $\begin{array}{l}\text { MPA } \\
\text { result }\end{array}$ & $\begin{array}{l}\text { report } \\
\text { hypothesis }\end{array}$ & $\begin{array}{l}\text { number of } \\
\text { speeding } \\
\text { offences }\end{array}$ & $\begin{array}{l}\mathrm{km} / \mathrm{h} \\
\text { above } \\
\text { speed limit }\end{array}$ & $\begin{array}{l}\text { temporal } \\
\text { distribution }\end{array}$ & $\begin{array}{l}\text { number of } \\
\text { non-speeding } \\
\text { offences }\end{array}$ & $\begin{array}{l}\text { participation } \\
\text { in traffic } \\
\text { therapy }\end{array}$ & $\begin{array}{l}\text { problem } \\
\text { awareness }\end{array}$ & self-criticism \\
\hline MPA result & 1 & $\begin{array}{l}\Phi=-.360 * * \\
\mathrm{p}<.001\end{array}$ & $\begin{array}{l}r=.011 \\
p=.912\end{array}$ & $\begin{array}{l}r=.002 \\
p=.983\end{array}$ & $\begin{array}{l}r=.081 \\
p=.422\end{array}$ & $\begin{array}{l}r=.044 \\
p=.665\end{array}$ & $\begin{array}{l}\Phi=.471 * * \\
\mathrm{p}<.001\end{array}$ & $\begin{array}{l}\Phi=.804^{* *} \\
\mathrm{p}<.001\end{array}$ & $\begin{array}{l}\Phi=.757 * * \\
\mathrm{p}<.001\end{array}$ \\
\hline $\begin{array}{l}\text { report } \\
\text { hypothesis }\end{array}$ & & 1 & $\begin{array}{l}r=-.001 \\
p=.989\end{array}$ & $\begin{array}{l}r=-.072 \\
p=.475\end{array}$ & $\begin{array}{l}r=-.109 \\
p=.279\end{array}$ & $\begin{array}{l}r=-.247^{*} \\
p=.013\end{array}$ & $\begin{array}{l}\Phi=.012 \\
p=.904\end{array}$ & $\begin{array}{l}\Phi=-.216^{*} \\
p=.030\end{array}$ & $\begin{array}{l}\Phi=-.267 * * \\
\mathrm{p}=.007\end{array}$ \\
\hline $\begin{array}{l}\text { number of } \\
\text { speeding } \\
\text { offences }\end{array}$ & & & 1 & $\begin{array}{l}r=.915^{* *} \\
p<.001\end{array}$ & $\begin{array}{l}r=-.129 \\
p=.200\end{array}$ & $\begin{array}{l}r=-.163 \\
p=.103\end{array}$ & $\begin{array}{l}r=-.045 \\
p=.655\end{array}$ & $\begin{array}{l}r=.066 \\
p=.513\end{array}$ & $\begin{array}{l}r=.012 \\
p=.905\end{array}$ \\
\hline $\begin{array}{l}\mathrm{km} / \mathrm{h} \text { above } \\
\text { speed limit }\end{array}$ & & & & 1 & $\begin{array}{l}r=-.025 \\
p=.803\end{array}$ & $\begin{array}{l}\mathrm{r}=-.258 * * \\
\mathrm{p}=.009\end{array}$ & $\begin{array}{l}r=-.057 \\
p=.573\end{array}$ & $\begin{array}{l}r=.023 \\
p=.822\end{array}$ & $\begin{array}{l}r=.013 \\
p=.900\end{array}$ \\
\hline $\begin{array}{l}\text { temporal } \\
\text { distribution }\end{array}$ & & & & & 1 & $\begin{array}{l}r=-.127 \\
p=.204\end{array}$ & $\begin{array}{l}r=-.024 \\
p=.810\end{array}$ & $\begin{array}{l}r=.040 \\
p=.691\end{array}$ & $\begin{array}{l}r=.060 \\
p=.549\end{array}$ \\
\hline $\begin{array}{l}\text { number of all } \\
\text { non-speeding } \\
\text { offences }\end{array}$ & & & & & & 1 & $\begin{array}{l}r=-.010 \\
p=.923\end{array}$ & $\begin{array}{l}r=.108 \\
p=.282\end{array}$ & $\begin{array}{l}r=.040 \\
p=.691\end{array}$ \\
\hline $\begin{array}{l}\text { participation } \\
\text { in driver } \\
\text { improvement } \\
\text { program }\end{array}$ & & & & & & & 1 & $\begin{array}{l}\Phi=.446^{* *} \\
\mathrm{p}<.001\end{array}$ & $\begin{array}{l}\Phi=.389 * * \\
p<.001\end{array}$ \\
\hline $\begin{array}{l}\text { problem } \\
\text { awareness }\end{array}$ & & & & & & & & 1 & $\begin{array}{l}\Phi=.740 * * \\
\mathrm{p}<.001\end{array}$ \\
\hline self-criticism & & & & & & & & & 1 \\
\hline
\end{tabular}

Note ${ }^{*} \mathrm{p}<.01,{ }^{*} \mathrm{p}<.05, \mathrm{~N}=101$

step one, since none of the regression weights are significant it can be concluded that the characteristics of the speeding offences and traffic delinquency history, indicative of speed-affine behaviours, alone do not predict the MPA result. When the reported hypothesis is added in step 2, the regression weight is significant and classification quality, as well as Nagelkerkes $\mathrm{R}^{2}$, increases moderately. A traffic psychological intervention program added in step 3 increases the classification quality to $80.2 \%$ and Nagelkerkes $\mathrm{R}^{2}$ to .475 . This is indicative of a good fit of the model to the data, which is not often reached in empirical settings. It also suggests that when MPA candidates participate at DIP the likelihood of a positive result notably increases. Finally, the addition of problem awareness and self-criticism in the fourth step lead to an almost perfect model fit. Since these aspects are essential for a positive MPA result, the result might not seem too surprising. However, the strength of the relationship between the two predictors and the outcome variable is quite high.

\section{SUMMARY AND CONCLUSIONS}

The aim of this study was to investigate the model fit of the medical-psychological assessment in Germany according to a standardized diagnostic process governed by guidelines and assessment criteria. More specifically, here we examined the predictors for the outcome of the MPA for a sample of speed-affine drivers who had previously had their licences revoked. We expected that speed offence-related characteristics and traffic delinquency history would not serve as predictors for the prognosis in future (represented by the outcome of the MPA).Instead we suggested that an individual learns to cope with their influencing factors from the maladaptive history with the help of a professional DI program (DIP), thus increasing their fitness to drive.

First, a correlation analysis was conducted. This revealed a positive correlation between a milder problem hypothesis (i.e. V3) and positive MPA outcome. A positive correlation was also observed between vol- 
Table 3: Hierarchical regression MPA result

\begin{tabular}{|c|c|c|c|c|}
\hline & predictors & $\mathrm{b}$ & Nagelkerkes $\mathrm{R}^{2}$ & quality of classification \\
\hline \multirow[t]{5}{*}{ Step 1} & number of speeding offences & .093 & .015 & $56.4 \%$ \\
\hline & $\mathrm{km} / \mathrm{h}$ above speedlimit & -.002 & & \\
\hline & temporal distribution & .720 & & \\
\hline & number of non-speeding offences & .052 & & \\
\hline & Constant & -.264 & & \\
\hline \multirow[t]{6}{*}{ Step 2} & number of speeding offences & .316 & .192 & $63.4 \%$ \\
\hline & $\mathrm{km} / \mathrm{h}$ above speedlimit & -.012 & & \\
\hline & temporal distribution & .515 & & \\
\hline & number of non-speeding offences & -.087 & & \\
\hline & hypothesis & $1.807^{* *}$ & & \\
\hline & constant & -.245 & & \\
\hline \multirow[t]{7}{*}{ Step 3} & number of speeding offences & .373 & .475 & $80.2 \%$ \\
\hline & $\mathrm{km} / \mathrm{h}$ above speedlimit & -.014 & & \\
\hline & temporal distribution & .823 & & \\
\hline & number of non-speeding offences & -.098 & & \\
\hline & hypothesis & $2.485^{* *}$ & & \\
\hline & participation in driver improvement program & $-2.682 * *$ & & \\
\hline & Constant & .791 & & \\
\hline \multirow[t]{9}{*}{ Step 4} & number of speeding offences & 1.285 & .927 & $95.0 \%$ \\
\hline & $\mathrm{km} / \mathrm{h}$ above speedlimit & -.035 & & \\
\hline & temporal distribution & -7.315 & & \\
\hline & number of non-speeding offences & .292 & & \\
\hline & hypothesis & $4.329^{*}$ & & \\
\hline & participation in driver improvement program & $-3.695^{*}$ & & \\
\hline & problem awareness & $-24.789 *$ & & \\
\hline & self-criticism & $-30.724^{*}$ & & \\
\hline & Constante & 53.185 & & \\
\hline
\end{tabular}

Note ${ }^{*} \mathrm{p}<.05,{ }^{* *} \mathrm{p}<.01$

untary participation at a DIP prior to the MPA and a positive MPA result. Finally, a positive correlation between a positive MPA outcome and problem awareness and self-criticism (both as demonstrated in the psychological interview) was observed. The results of the regression suggested that speed-affine driving style and the sum of offences (as retrieved from official record files) do not predict the outcome of the MPA. Further, they also suggest that those individuals who attended a driver intervention program prior to undergoing the MPA were more likely to achieve a positive result on the MPA, i.e., they were more likely to get their driving licence returned.

Given that the variables added in step 1 of the regression explain almost none of variance in the MPA result, it can be suggested that a positive MPA result is nearly independent of offence-related characteristics (e.g. speeding offences and delinquency history). Taken together with the finding that problem awareness and self-criticism (as judged by the psychological assessment) and participation in DIP does predict MPA outcome, the present results suggest that the 
MPA is a valid tool to help improving road safety, since high risk drivers are excluded from traffic (i. e. due to a negative MPA outcome, their driving licence is not regranted by the authority). These are positive news for the German MPA and Rehabilitation System, suggesting that the MPA can be interpreted not as a punishment but as a chance for an offender to regain his licence upon the provision that they are fit to drive (again).

It is worth noting, that problem hypothesis (V1 to V3) only moderately predicted the MPA result, it is harder for those with a more severe hypothesis to achieve a positive MPA. Therefore, we recommend that these offenders participate in DIP, especially when there is a reduced adjustment ability to traffic rules (i.e. people having received hypothesis V2). DIP allows the offender to reflect on past attitudes and behaviour, learn why they were wrong and build new lasting strategies to deal with emotions while driving. This process is important for the MPA result; hence DIP participation is a strong predictor of MPA outcome. Problem awareness and self-criticism demonstrated in the psychological interview were the strongest predictors for a positive MPA result, not surprisingly, since a positive result is not possible without changing cognitive factors. A possible recommendation is to focus especially on these two aspects in traffic psychological therapy.

\subsection{Limitations}

There are a few limitations in the present study that should be addressed. First, data was taken from existing records; as such there was no experimental manipulation. Second, the sample was restricted to 101 subjects who were examined in the same assessment institute in the capitol city of Saxony (Dresden). A larger and representative sample would be more favourable; however, this research is the first of its kind and will path the way for larger future studies on the MPA. Third, due to restricted personnel resources, the data were coded by one researcher. As such, no interrater-reliability could be computed. However to negate the possibility of coding errors and biases, a strict coding plan was utilized. This relied mostly on objective measures and the MPA report, which offered a detailed description and explanation of the findings. Afinal potential confound is that the MPA result is not only reliant on the change in behaviour. To achieve a positive prognosis, all criteria have to be confirmed, even those from the areas of medical and performance testing. However, health or psycho-functional impairments were not considered in this study.

\subsection{Implications for the future}

Speeding is a serious, yet common offence. So far, relatively little empirical research has been conducted in Germany, especially amongst MPA candidates. To the authors' knowledge, this is the first empirical study to examine traffic offenders, particularly speed-affine drivers, in relation to their MPA outcome. As our sample size was relatively small, future studies however could use a larger sample size. It would also be interesting to make an international comparison of traffic rehabilitation measures. The current findings also strongly suggest that participating in a DIP should be recommended for all those who are going to undertake the MPA. The DIP should focus especially on problem awareness and self-criticism since those were found to be the best predictors of MPA result. It might also be considered that offenders with V2 hypothesis are supervised after the MPA, for example, they could be given a mandatory traffic therapy consultation six months later in order to further stabilize the changing process. The penalty point system could consist of voluntary and mandatory intervention measures earlier in the offender's biography. Sadly, speeding is a widely spread and dangerous behaviour, yet interventions are relatively mild in Germany, with consequences only occurring after reaching the fairly generous limit of 8 penalty points.

The current composition of maladaptive drivers influencing measures should be reflected by the administration and there might be a rethinking towards the usefulness of mandatory DIP before reaching the red line of 8 penalty points.

\section{REFERENCES}

Berry, T. D., Johnson, K. L., Porter, B. E. (2011). Speed(ing). AQuality Control Approach. In: Porter, B.E. (Ed.). Handbook of traffic psychology. 1st ed., Academic Press London, Waltham, MA, pp. $249-365$.

Brenner-Hartmann, J., Wagner, T., Mußhoff, F., HoffmannBorn, H., Löhr-Schwaab, S., \& Seidl, J. (2014). Assessment of personal resources for safe driving. The principles of medical psychological assessment in Germany. Schriftenreihe Fahreignung. Bonn: Kirschbaum Verlag.

Bundesanstalt für Straßenwesen (201). Begutachtungsleitlinien zur Kraftfahreignung. Bergisch Gladbach: Fachverlag NW in der Carl Schünemann Verlag GmbH. 
Bundesanstalt für Straßenwesen (2018). MPU 2017: Zahl der Medizinisch-Psychologischen Untersuchungen sinkt. Retrieved from: https://www.bast.de/BASt_2017/DE/Presse/Mitteilungen/2018/presse-08-2018.html

Deutsche Gesellschaft für Verkehrspsychologie (DGVP) \& Deutsche Gesellschaft für Verkehrsmedizin (DGVM). (2013). Urteilsbildung in der Fahreignungsbegutachtung-Beurteilungskriterien. Bonn: Kirschbaumverlag.

Groeger, J. A. (2011). How many E's in road safety?. In B. E. Porter (Ed.), Handbook of traffic psychology (pp. 3 - 12). (2011). Amsterdam: Elsevier.

Hössinger, R. \& Berger, W.J. (2012). Stated response to increased enforcement density and penalty size for speeding and driving unbelted. Accident Analysis \& Prevention, 49, 501 - 511.

Kloeden, C. N., McLean, A. J., Moore, V. M. \& Ponte, G. (1997) Travelling speed and the rate of crash involvement. Volume 1: findings. Report No. CR 172. Federal Office of Road Safety FORS, Canberra

Kraftfahrt-Bundesamt (2018). Verkehrsauffälligkeiten (VA)- Bestand im Fahreignungsregister 1. Januar 2017. Retrieved from https://www.kba.de/DE/Statistik/Kraftfahrer/Verkehrsauffaelligkeiten/Bestand_FAER_VZR/bestand_faer_node.html

Rößger, L., Schade, J., Schlag, B. \& Gehlert, T. (2011). Verkehrsregelakzeptanz und Enforcement. GDV (Forschungsbericht des Gesamtverbands der Deutschen Versicherungswirtschaft e. V.). Report Nr. 6. Berlin

SafetyNet. (2009). Speeding. Retrieved from https://ec.europa. eu/transport/road_safety/sites/roadsafety/files/specialist/ knowledge/pdf/speeding.pdf

SARTRE III. (2004). European drivers and road risk; Part 1: report on principal results. Paris: INRETS

Shinar, D. (2017). Traffic Safety and human behavior. 2nd edition. Bingley (UK): Emerald Publishing Limited.

Sucha, M. \& Cernochova, D. (2016). Driver personality as a valid predictor of risky driving. Transportation research Proceedings, 14, $4286-4295$.

Wagner, T., Keller, M. \& Jäncke, L. (2018). Impulsivity subtypes and maladaptive road performance among drivers in Germany and Switzerland. Journal of Traffic and Transportation Engineering (paper accepted and in press).

Watson, B., Watson, A., Siskind, V., Fleiter, J., \& Soole, D. (2014). Profiling high-range speeding offenders: Investigating criminal history, personal characteristics, traffic offences, and crash history. Accident Analysis \& Prevention, 74, 87 - 96. 